\title{
Exploration on Innovative Teaching Mode of Three- dimensional Cutting Course in Fashion Design
}

\author{
Huaxia Zhang \\ Jiangxi Institute of Fashion Technology \\ Nanchang, China 330201
}

\begin{abstract}
With the diversified development of the clothing industry, the plane cutting will not meet the requirements of fashion styling on structure. The three-dimensional cutting has been widely used in clothing structure design. Due to the complex operations, there may be all kinds of drawbacks in teaching of three-dimensional cutting. Starting from drawbacks in the teaching of three-dimensional cutting in fashion institutes, the paper has analyzed the causes of drawbacks, made an innovative exploration on the teaching mode of this course and put forward a new teaching mode.
\end{abstract}

Keywords-fashion design specialty; three-dimensional cutting; innovative teaching mode; exploration

\section{INTRODUCTION}

The three-dimensional cutting for clothing is one of the clothing structure formation methods. Modern fashion styling has more and more requirements on structure. The threedimensional cutting has been integrated into fashion design. In this situation, the fashion institutes shall improve their requirements on their students' comprehensive ability in operating three-dimensional cutting. At present, the domestic three-dimensional cutting education for clothing has the following modes.

- Take plane cutting as primary in the first academic year, and add three-dimensional cutting in the second academic year. Lay equal stress on plane cutting and three-dimensional cutting in teaching in late period.

- Take three-dimensional cutting as primary in the first academic year, and lay equal stress on plane cutting and three-dimensional cutting in teaching in the middle and late period.

- Take plane cutting as primary in the first and second academic year, and add three-dimensional cutting in the late period. Lay particular stress on plane cutting in the whole teaching process, and regard threedimensional cutting as complementary.

The main teaching content of this course: in the first step, let students know human body or styling, line and data of manner through practical teaching. It can lay a foundation for later styling. In the second step, teach students how to use three-dimensional cutting skills and directly operate cloth on human body or mannequin without any data, transforming imagination into styling. In the third step, after mastering basic styling and operation methods, further improve students' adaptability to changes and styling analysis ability, and gradually improve students' practical operation ability in threedimensional cutting.

\section{The Teaching Status AND Disadvantages of THREE-DIMENSIONAL CUTTING COURSE}

\section{A. The Curriculum Setting, Unable to Be Docked to Students' Cognition on Human Body Structure}

Most of domestic fashion professional institutes take plane cutting as primary and three-dimensional cutting as complementary, so their students learn plane formation of clothing in the first academic year in curriculum setting. Students with some foundation on fashion have no problem in such curriculum setting. But most of students in fashion institutes are graduated from high school and they directly enter into fashion institute for study. And they have no foundation and knowledge on human body structure. If directly use data to teach plane structure design, these zerobased students cannot combine three-dimensional structure of human body with plane design. They can only memorize design data mechanically. They can make design according to same data, but they can hardly combine human body structure with plane design. In this case, the teaching will be boring, and students may lose confidence in learning.

\section{B. The Styling in Teaching Process, Unable to Be Docked to the Market Needs}

In the three-dimensional cutting course, the styles teachers use are basically standard styles with no big change. They ignore the actual demand of the market and emphasize the operation of styling in teaching. The teaching achievements only stay in the mannequin display stage, which cannot perfect the formation and accuracy of industrial pattern in the late period. The three-dimensional cutting process students master is not complete, and teaching styles cannot be used in real production process. The theories cannot be well docked to reality. With little change in teaching styles, the limited class hours limit the diversity of styling explanation process. Students' operation ability in three-dimensional cutting basically stays in learning prepared lessons. 


\section{Less Three-dimensional Cutting Used in Practice, Resulting in the Lack of Practical Experience of Students}

In the teaching process of three-dimensional cutting, teachers usually explain and demonstrate, and students operate based on the finished models. The thinking mode of students formed in this process only stays on imitation. There is no innovation. Students don't need to use their thinking to interpret and analyze styles. The extension of knowledge is broken. The imitation process is boring for students, and it cannot form a coherent knowledge system. In the process of three-dimensional cutting, most of students' work needs to be finished with cloth. Students are not good at accuracy of technology and perfection of pattern processing, resulting in large outline and poor details. If things go on like that, the students' learning achievement cannot be ascended, and it weakens the enthusiasm of the students.

\section{EXPLORATION ON THE INNOVATIVE TEACHING MODE OF THREE-DIMENSIONAL CUTTING}

\section{A. Dividing the Course of Three-dimensional Cutting and Inserting into the Course of Plane Cutting in Different Stages}

Students in fashion institutes in early stage have not formed any concept on human body structure. If we carry out three-dimensional cutting and plane cutting in two separate stages, we cannot make their respective advantages complementary to each other. The most complete formation method is to combine them together. We can divide threedimensional cutting course into several parts and insert them into the course of plane cutting. It can not only improve students' intuitive understanding on structure, but also improve the fashion styling ability of students. The simultaneous march of plane cutting and three-dimensional cutting can increase students' interest in learning structure. The majority of domestic fashion institutes carry out plane cutting course first and then three-dimensional cutting course. The two courses are independent modules with no relationship in curriculum setting. Most of foreign fashion teachings start from threedimensional cutting. It is the first step for students of fashion design to know human body structure. The plane cutting has the characteristics of low cost and high efficiency. The visualizability of three-dimensional cutting is higher than that of plane cutting. The combination of both of them can greatly improve students' cutting ability and accuracy of industrial pattern. It is very common for the combination to apply in real production. Therefore, the combination of the two cutting methods in curriculum setting can not only improve students' understanding on human body structure and relevant data, but also establish students with the concept of the combination use of the two cutting methods.

\section{B. Improving the Teaching Condition to Make the Teaching Process More Clear and Direct to Students}

Theoretical knowledge of three-dimensional cutting accounts for a small portion. Nearly $80 \%$ is practice. It belongs to a strongly practical course. In class, teachers usually operate, demonstrate and then explain and analyze the difficulties and key points and making process to students. After explanation, students carry out practice and they make styles according to teacher's operation. Where are the drawbacks of such teaching? There are at least twenty or thirty students in class. If they all surround the teacher, only students near teachers can see the operating process clearly. Students behind or in the peripheral side cannot see the details and steps of the operation, so they can generally finish teacher's teaching style in the later making process. In this process, we can use multi-media to teach students and enlarge the operating process of teacher on screen with camera, so that students can see the direct operating process through screen. This problem can be well solved no matter how many students are there in the class. The most important is that students can see details clearly and may not have a smattering of knowledge. At the same time, teachers can make plane and three-dimensional patterns into PPT and put on the screen for comparison. It will help students understand the transformation between 2D and 3D.

\section{Combining and Updating Teaching Styles according to the Market Demands}

The styles used in three- dimensional cutting teaching process mainly are basic styles with not many changes in the contents. Due to the limit of class hours, the teaching content is not undated accordingly. Students only imitate and don't innovate. The works of students only can be applied on mannequin, and cannot be used as industrial patterns. The present market has higher and higher requirements on fashion styles. The operation only staying on basic styles cannot meet the market demand for fashion styles. In the formulation of the professional direction of three-dimensional cutting, we should accurately position, combine production, teaching and research, and really apply our knowledge into practice.

Teaching content is divided into several parts, from basic to deep, step by step. The combination of both can train and improve students' practical ability. In the late threedimensional cutting stage, we can use current popular styles, and introduce the research projects of enterprise into teaching by cooperating with enterprises. Allow students participate in the research and development project. The projects of enterprise are docked with market, so they are flexible. In the participation, students can improve their basic styling skill and contact with the market directly. When they graduate they may handle their job easily. It is conducive to students' employment. If there is no research and development project of enterprise, we can carry out simulative enterprise evaluation in class, start from perfecting the evaluation system of threedimensional cutting course and improve students' awareness on fashion and hands-on operation ability.

\section{Introducing Competitions to Promote Students, Professional Skills and the Curriculum Construction}

In the curriculum setting, we can introduce competitions in the parallel classes. Take a teaching unit as an example or take a competition as theme to set the competition items. The competitive styles shall be combined with market. In the early stage, we can give corresponding training on students. The competition results can also be used in students' final evaluation system by percentage, and thus stimulate the enthusiasm of students from multiple perspectives. We can 
give students targeted unit practice which can not only strengthen the practical ability of students, but also improve their creative ability and ability in grasping styling. It can not only check students' learning effect but also can help teachers exchange their teaching experience to introduce competitions in parallel class. We can use competitions to promote students' professional skills and the curriculum construction. We can exhibit students' works after competition and enable students to find gap and shortcomings from finished works and improve themselves through exchange and practice.

\section{E. Laying Particular Stress on Fashion Styling Display in Teaching Process of Three-dimensional Cutting}

Some fashion styles are suitable for ready-made clothes for market, some for stage and film and television drama. For styles of ordinary ready-made clothes for market, to use plane cutting is faster than to use three-dimensional cutting. For complex, changeable and even exaggerated styles, to use threedimensional cutting is better than to use plane cutting. This general pattern results in that teachers form a conventional concept in teaching: three-dimensional cutting is only suitable for exaggerated and complex styles, but not for relative conventional and normative ready-made fashion styles. They overemphasize the importance of styling in three-dimensional cutting teaching. Students boldly design styling, but they cannot make pattern, and only put the finished style on mannequin. They neglect the demand of human body for functions in the try-on process. The formalization is very serious. They are divorced from reality. Second, the plane cutting is not well combined into the teaching of threedimensional cutting. So, the data of detail parts are not accurate and precise. The combination of both can enhance the accuracy of styling.

\section{CONCLUSION}

The fashion institutes should lay emphasis on training students' practical operation ability in setting up threedimensional cutting course. The market and enterprises have higher and higher requirements on students, so that fashion institutes shall improve their teaching quality of professional courses to help students meet the requirements of market and enterprises. In the course of three-dimensional cutting, teachers should train students' practical operation ability and artistic aesthetic ability, so that they can design style well. What's more, they should also well process the relationship of details and integrity. The purpose of three-dimensional cutting is to help students better make fashion design. To master the methods and skills of three-dimensional cutting is very important. The key is to improve students' creative ability and ability in grasping the beauty of integral styling. Only by combining right teaching goal, content and methods, can we improve the teaching effect of three-dimensional cutting course.

\section{REFERENCES}

[1] Edited by Deng Pengju \& Wang Xuefei. Three-dimensional Cutting of Fashion. Beijing: Chemical Industry Press. August 2011.
[2] Edited by Zhang Wenbin. Three-dimensional Cutting of Fashion. Shanghai Science and Technology Press, 2001.

[3] Edited by Zhou Wenhui. Three-dimensional Cutting Methods. Jiangxi Science and Technology Press. August 2008.

[4] He Junlian. Teaching Status and Teaching Reform of Threedimensional Cutting Course in Higher Vocational Education. Shandong Textile Economy, 2011. 